\title{
A Successfully Treated Case of Recurrent Focal Segmental Glomerulosclerosis (FSGS) with Plasmapheresis and High dose Methylprednisolone Pulse Therapy
}

\author{
Sun Mi Her, M.D. ${ }^{1}$ \\ Keum Hwa Lee, M.D. ${ }^{1,2,3}$ \\ Jae Il Shin, M.D., Ph.D. ${ }^{1,2,3}$ \\ Department of Pediatrics' ${ }^{1}$, Yonsei \\ University College of Medicine, \\ Seoul, Korea, Division of Pediatric \\ Nephrology'2, Severance Children's \\ Hospital,Seoul, Korea, Institute of \\ Kidney Disease Research ${ }^{3}$, Yonsei \\ University College of Medicine, Seoul, \\ Korea
}

Corresponding author: Jae II Shin, M.D., Ph.D.

Department of Pediatrics, Yonsei

University College of Medicine, 50-1

Yonsei-ro, Seodaemun-gu, Seoul 03722,

Korea

Tel: +82-2-2228-2050

Fax: +82-2-393-9118

E-mail:SHINJI@yuhs.ac

Received: 4 October 2017

Revised: 6 October 2017

Accepted: 7 October 2017
This is an open-access article distributed under the terms of the Creative Commons Attribution Non-Commercial License (http:// creativecommons.org/licenses/by-nc/4.0/) which permits unrestricted non-commercial use, distribution, and reproduction in any medium, provided the original work is properly cited.

Copyright (C) 2017The Korean Society of Pediatric Nephrology
Focal segmental glomerulosclerosis (FSGS) in children, which is a kind of nephrotic syndrome showing steroid resistance, usually progresses to a substantial number of end stage renal disease (ESRD). Although the pathogenesis of primary FSGS is unclear, several recent studies have reported that FSGS is associated with circulating immune factors such as soluble urokinase-type plasminogen activator receptor (suPAR) or anti-CD40 autoantibody. We report a successfully treated case of a 19-year-old female patient who experienced a recurrence of primary FSGS. After the diagnosis of FSGS, the patient progressed to ESRD and received a kidney transplantation (KT). Three days later, recurrence was suspected through proteinuria and hypoalbuminemia. She has been performed plasmapheresis and high dose methylprednisolone pulse therapy and shown remission status without increasing proteinuria for four years after KT. In conclusion, strong immunosuppressive therapy may be helpful for a good prognosis of recurrent FSGS, suppressing several immunologic circulating factors related disease pathogenesis.

Key words: Focal segmental glomerulosclerosis (FSGS), End stage renal disease (ESRD), Soluble urokinase-type plasminogen activator receptor (suPAR), Anti-CD40 autoantibody

\section{Introduction}

Idiopathic nephrotic syndrome is the most common glomerular disease in children. Also, congenital anomalies of the kidney and urinary tract are the most common cause of end-stage renal disease (ESRD) in children, followed by focal segmental glomerulosclerosis (FSGS) that is a kind of intractable glomerular disease ${ }^{1)}$. FSGS is one of the steroid resistant nephrotic syndromes and accounts for about $20 \%$ of children with nephrotic syndrome and about $50 \%$ of them progress to $\mathrm{ESRD}^{2,3)}$.

According to reports of the causes of FSGS, the main cause of primary FSGS is thought to be a podocyte injury by several circulating factors. The proposed caused of secondary FSGS are genetic, virus infections (e.g., human immunodeficiency virus type 1 , parvovirus $B 19$, simian virus 40 , cytomegalovirus, Epstein-Barr virus), drugs (e.g., heroin, interferons alfa, beta, and gamma, lithium, pamidronate, sirolimus, calcineurin-inhibitor nephrotoxicity, anabolic steroids) and adaptive (reduced renal mass and renal hypertension) ${ }^{2}$. 
Steroid resistant FSGS in children usually gradually progresses to ESRD and needs to be received renal replacement therapies such as dialysis or kidney transplantation (KT). Even the patient has been performed KT recurrence rate is about $20-50 \%{ }^{4}$.

Although the pathological mechanism of recurrent FSGS has not yet been elucidated, previous studies have reported that proteinuria occurs when injected into rats with serum from FSGS patients ${ }^{5}$. Recently, it has been reported that increased soluble urokinase-type plasminogen activator receptor (suPAR) affects the pathogenesis of kidney disease, especially FSGS ${ }^{6}$. In addition, there are studies that antiCD40 autoantibody may be a potential circulating factor related to FSGS disease pathogenesis ${ }^{7,8)}$.

This report describes a case of successful treatment with plasmapheresis and high dose immunotherapy to strongly control immunologic circulating factors in recurrent FSGS patients after KT.

\section{Case report}

A 2-year-old female was diagnosed with nephrotic syndrome in February 2000 and had no family history. The patient was treated with deflazacort, but edema and proteinuria were repeatedly relapsed. Renal biopsy was performed in November 2000 for further evaluation of recurrence and minimal change disease was diagnosed. After that, methylprednisolone (MP) pulse therapy was performed and cyclosporine was added, but proteinuria, facial edema, hypoal- buminemia did not be improved continuously. Therefore, a second renal biopsy was performed in October 2001 for evaluation and FSGS was finally diagnosed.

After FSGS diagnosis, 6 cycles of MP pulse therapy (30 $\mathrm{mg} / \mathrm{kg}$ ) and 6 cycles of cytoxan pulse therapy (500 mg/BSA) were performed (from November 2001 to April 2002), and deflazacort and cyclosporine were maintained. However, relapses were repeated even though mycophenolate mofetil was added from September 2005 and eventually the disease progressed to ESRD. Eventually, at the age of 15, she received bilateral nephrectomy and living related donor KT in February 2013 . The allograft functioned well immediately after reperfusion, but symptoms of nephrotic syndrome such as massive proteinuria exceeding $14 \mathrm{~g} / \mathrm{d}$, hypoalbuminemia (serum albumin $2.2 \mathrm{~g} / \mathrm{dL}$ ) and hypercholesterolemia (cholesterol $247 \mathrm{mg} / \mathrm{dL}$ ) appeared on day 3 after KT. Three courses of plasmapheresis were tried at first, but they were ineffective. So the patient received a drug regimen with infusions of $20 \mathrm{mg} / \mathrm{kg}$ MP pulse therapy for 3 consecutive days every two weeks until 6 months after transplantation. After 6th infusion of pulse therapy, a graft function rapidly recovered and immediate reduction of serum creatinine and proteinuria was appeared. The patient achieved complete remission of proteinuria with stable renal function within 4 months of beginning of treatment. Four years after transplantation, no signs of FSGS recurrence are evident and graft function remains good (Fig. 1). Currently, the patient maintains taking immunosuppressants (tacrolimus, prednisolone, and mycophenolate) for preventing transplant rejection.

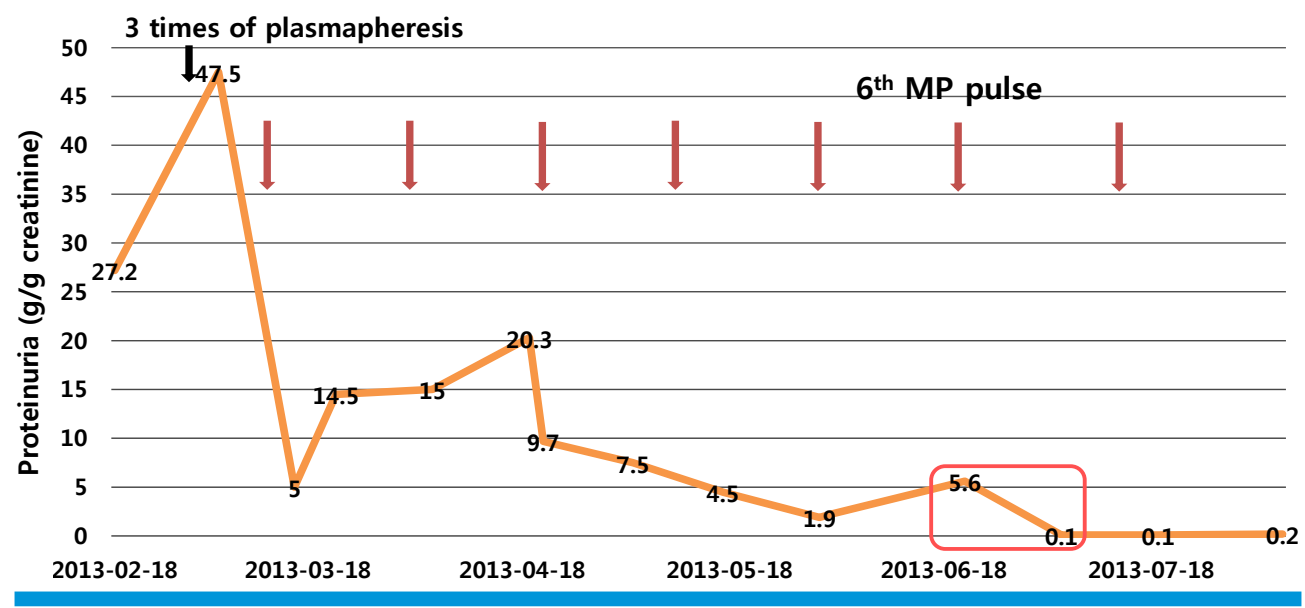

Fig. 1. Clinical course of treatment to the patient with recurrence of 3 days after receiving KT. FSGS, focal segmental glomerulosclerosis; KT, kidney transplantation; MP, methylprednisolone. 


\section{Discussion}

The recurrence rate of primary FSGS after KT is relatively high, reported from 20 to $50 \%$ of patients ${ }^{4)}$. It is known that two kinds of presentations can be came out after KT: an early recurrence and a late recurrence. Early recurrence can be frequently developed in about 10-18 days after KT, characterized by a nephrotic range of proteinuria with development of histological lesions of the new kidney ${ }^{9)}$. In contrast, patients with a late recurrence shows massive proteinuria within several months or years after $\mathrm{KT}^{9)}$. The graft survival is poor in children with recurrence of FSGS after KT because reported the median survival is only 5 months ${ }^{10)}$. The risk of graft failure is higher in children with an early recurrence than a late one ${ }^{11)}$.

Despite the high incidence of recurrence and graft failure of FSGS after KT, however, the pathogenesis of recurrent FSGS is not well established from now on. In recent studies, several circulating factors have been suggested as a key role in the disease mechanism of FSGS ${ }^{7,12)}$. Several circulating factors which have been proposed are as follows: (1) suPAR and (2) anti-CD40 autoantibody.

SuPAR is released from the component of UPAR, which is the receptor of urokinase-type plasminogen activator (uPA) system ${ }^{13)}$. In 2011, Wei et al. firstly reported that FSGS patients have two-thirds of elevated levels of suPAR and suggested that circulating suPAR could be a predictive value of FSGS recurrence in $\mathrm{KT}^{14)}$. They hypothesized that suPAR enters the kidney glomerulus and activates $\beta 3$ integrin, which is the major anchoring proteins in glomerular basement membrane of podocyte ${ }^{14)}$. Thus, podocyte dysfunction and effacement of membrane are developed resulting proteinuria ${ }^{14)}$. There have been controversies, however, that suPAR levels can be increased not only in FSGS but also in other glomerular diseases or other systematic diseases such as paroxysmal nocturnal hemoglobinuria, infectious diseases including Human Immunodeficiency Virus (HIV)-1, tuberculosis sepsis, and malignancies ${ }^{13,15)}$. In addition, high-serum suPAR can show inverse correlation with estimated glomerular filtration rate $(\mathrm{GFR})^{16)}$.

Anti-CD40 autoantibody is also known as a circulating factor as an additional therapeutic target which cooperates with circulating suPAR with developing podocyte injury and proteinuria ${ }^{8)}$. In animal models, injecting anti-CD40 autoantibody developed FSGS and some cases improved by manipulation of humoral response with plasmapheresis and rituximab ${ }^{17,18)}$. Besides, there is a report that recurred FSGS after KT was cured by plasmapheresis and rituximab ${ }^{19)}$.

In our case, the patient showed massive proteinuria within three days after KT suggesting an early recurrence of FSGS. She has a high risk of graft failure, so we performed plasmapheresis and high-dose methylprednisolone protocol to reduce circulating factors. These treatment was effective because she shows maintainance of remission status without increasing proteinuria for three years after KT. This case suggests that the pathogenesis of recurrence can be related to immune mechanisms and serological dysregulation due to circulating factors. Also, high-dose methylprednisolone pulse therapy may have threshold dose of inducing remission. In other words, if immunesuppressants are not enough to suppress these relating circulating factors, the disease can relapse more often.

In conclusion, we should consider strong immunosuppressive therapy as soon as the patient with FSGS showing recurrence before proceeding to ESRD. The good response to the high-dose methylprednisolone combined plasmapheresis may suggest the autoimmune nature of FSGS relating immunologic circulating factors.

\section{Conflicts of interest}

No potential conflict of interest relevant to this article was reported.

\section{References}

1. Harambat J, van Stralen KJ, Kim JJ, Tizard EJ. Epidemiology of chronic kidney disease in children. Pediatr Nephrol 2012;27:36373.

2. D'Agati VD, Kaskel FJ, Falk RJ. Focal segmental glomerulosclerosis. N Engl J Med 2011;365:2398-411.

3. Niaudet P. [Lipoid nephrosis in childhood]. Rev Prat 2003;53:202732.

4. Cochat P, Fargue $S$, Mestrallet $G$, Jungraithmayr T, Koch-Nogueira $\mathrm{P}$, Ranchin B, et al. Disease recurrence in paediatric renal transplantation. Pediatr Nephrol 2009;24:2097-108.

5. Zimmerman SW. Increased urinary protein excretion in the rat 
produced by serum from a patient with recurrent focal glomerular sclerosis after renal transplantation. Clin Nephrol 1984;22: 32-8.

6. Hayek SS, Sever S, Ko YA, Trachtman H, Awad M, Wadhwani S, et al. Soluble Urokinase Receptor and Chronic Kidney Disease. N Engl J Med 2015;373:1916-25.

7. McCarthy ET, Sharma M, Savin VJ. Circulating permeability factors in idiopathic nephrotic syndrome and focal segmental glomerulosclerosis. Clin J Am Soc Nephrol 2010;5:2115-21.

8. Delville M, Sigdel TK, Wei C, Li J, Hsieh SC, Fornoni A, et al. A circulating antibody panel for pretransplant prediction of FSGS recurrence after kidney transplantation. Sci Transl Med 2014;6:256ra136.

9. Cochat P, Schell M, Ranchin B, Boueva A, Said MH. Management of recurrent nephrotic syndrome after kidney transplantation in children. Clin Nephrol 1996:46:17-20.

10. Ehrich JH, Rizzoni G, Brunner FP, Brynger H, Geerlings W, Fassbinder W, et al. Combined report on regular dialysis and transplantation of children in Europe, 1989. Nephrol Dial Transplant 1991;6 Suppl 1:37-47.

11. Baum MA. Outcomes after renal transplantation for FSGS in children. Pediatr Transplant 2004;8:329-33.

12. Reiser J, Nast CC, Alachkar N. Permeability factors in focal and segmental glomerulosclerosis. Adv Chronic Kidney Dis 2014;21: $417-21$.
13. Thuno M, Macho B, Eugen-Olsen J. suPAR: the molecular crystal ball. Dis Markers 2009;27:157-72.

14. Wei C, El Hindi S, Li J, Fornoni A, Goes N, Sageshima J, et al. Circulating urokinase receptor as a cause of focal segmental glomerulosclerosis. Nat Med 2011;17:952-60.

15. Sever $\mathrm{S}$, Trachtman $\mathrm{H}$, Wei $\mathrm{C}$, Reiser J. Is there clinical value in measuring suPAR levels in FSGS? Clin J Am Soc Nephrol 2013;8:12735.

16. Harita Y, Ishizuka K, Tanego A, Sugawara N, Chikamoto H, Akioka $Y$, et al. Decreased glomerular filtration as the primary factor of elevated circulating suPAR levels in focal segmental glomerulosclerosis. Pediatr Nephrol 2014;29:1553-60.

17. Fornoni A, Sageshima J, Wei C, Merscher-Gomez S, AguillonPrada R, Jauregui AN, et al. Rituximab targets podocytes in recurrent focal segmental glomerulosclerosis. Sci Transl Med 2011;3: 85 ra46.

18. Assmann KJ, van Son JP, Dijkman HB, Mentzel S, Wetzels JF. Antibody-induced albuminuria and accelerated focal glomeruloselerosis in the Thy-1.1 transgenic mouse. Kidney Int 2002;62:11626.

19. Hristea D, Hadaya K, Marangon N, Buhler L, Villard J, Morel P, et al. Successful treatment of recurrent focal segmental glomeruloselerosis after kidney transplantation by plasmapheresis and rituximab. Transpl Int 2007;20:102-5. 